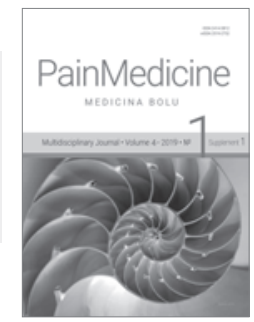

DOI: 10.31636/pmjua.t2.1

\title{
Efficiency of meloxicam application in complex treatment of patients with osteoarthrosis combined with hypertension
}

\author{
Kuznecova L. P., Bondar M. V. \\ State institution "Zaporizhzhya Medical Academy of Postgraduate Education", Zaporizhzhya, Ukraine
}

Objective: To evaluate the efficacy of the therapy performed 12 months after initiation of treatment in patients with osteoarthrosis (OA) combined with hypertension (GC) with treatment with meloxicam at a dose of 7.5 $\mathrm{mg} /$ day and $80 \mathrm{mg} /$ day and $160 \mathrm{mg} /$ day "difores".

Material and methods: under observation in outpatient settings, there were 60 patients on OA 1-2 stages, in combination with GC 2 degree, 2-3 degrees. The average age of patients with OA was $64.4 \pm 7.5$ years, patients with $\mathrm{OA}$ in combination with $\mathrm{GC}$ $62.13 \pm 8.2$ years $-41(68.3 \%)$ women and $19(31.7 \%)$ men. Duration of the disease was in patients with $\mathrm{OA}-(9.66 \pm 4.7)$ years, in patients with a comorbidity of OA and GC $-(9.4$ \pm 6.0 ) years, respectively.

To perform the research tasks, all patients were divided into 3 groups of 30 patients in each of them. The first group - patients with $\mathrm{OA}$ without GC, the second one - patients with a combination of $\mathrm{OA}$ and $\mathrm{GC}$, the third group of comparison contained practically healthy persons.

All patients complained of pain syndrome of varying degrees of severity. Patients of the first two groups received methoxy at a dose of $7.5 \mathrm{mg}$ per day as baseline therapy; meloxicam and antihypertensive drug "diforsi" at a dose of $80 \mathrm{mg}$ per day - patients in the second group were taken, but in $29 \%$ of patients in this group "diormos" was prescribed at a dose of $160 \mathrm{mg}$. Duration of treatment was 12 months.

A general clinical examination was performed inall patients at the beginning of the study, and after treatment: general blood tests, office blood pressure measurements, electrocardiography (ECG), daily blood pressure monitoring (DMAT), radiography of the knee joints.

Results: 1. According to the results, the positive effect of using meloxicam caused a significant decrease in the severity of pain in the first and second groups according to the visual analog scale (VAS): (by $27.8 \%$ and $29.8 \%$ respectively, $p<0.05)$ and the Lequesne index (respectively $27.1 \%$ and $30.9 \%$, $\mathrm{p}<0.05$ ).

2. Also, the analgesic and anti-inflammatory effect of meloxicam and its positive effect on the clinical course of $\mathrm{OA}$ were revealed: joint pain decreased, functional capacity increased, general well-being and quality of life of patients improved. 